“ (C) 2017 IEEE. Personal use of this material is permitted. Permission from IEEE must be obtained for all other uses, in any current or future media, including

reprinting/republishing this material for advertising or promotional purposes, creating new collective works, for resale or redistribution to servers or lists, or reuse of any copyrighted component of this work in other works." 


\title{
The Relationship of Calculated and Perceived Distance Dimensions in Interdisciplinary Collaborations: Evidence from a Battery Research Project
}

\author{
Nicole vom Stein ${ }^{1}$, Nathalie Sick ${ }^{1,2}$, Jens Leker ${ }^{1}$ \\ ${ }^{1}$ Institute of Business Administration at the Department of Chemistry and Pharmacy, \\ University of Muenster, Muenster, Germany \\ ${ }^{2}$ Helmholtz Institute Muenster (HI MS), IEK-12, Forschungszentrum Juelich, Muenster, Germany
}

\begin{abstract}
Innovation collaborations experienced a substantial growth, so that the research interest in factors contributing to successful collaboration increased. One important factor in this context are distances like technological and geographical distance. The distinction between objectively calculated and individually perceived distances provides possible starting points to bridge high distances. Therefore, the study at hand aims to answer the following research question: How are calculated technological and geographical distances related to their perceived counterpart and how do these different distance dimensions influence each other?

The data is collected from an interdisciplinary battery research project. The calculated technological distance is measured via a publication-based approach while the calculated geographical distance is defined as the distance between the respective working places. Perceived distances, in contrast, are received via an online questionnaire. The influence model confirms a positive relationship between the calculated distance dimensions, technological and geographical distance, and their perceived counterparts. However, respective measures do by far not entirely overlap, so that the perceived ones are further influenced by factors like e.g. scientific background or shortest travel time. This approach is especially promising to foster social innovation as the awareness of bridging mechanisms might provide avenues to deal with technological distance, which can be assumed to be comparably high in this context.
\end{abstract}

\section{INTRODUCTION}

According to Katz and Martin [36] "a 'research collaboration' could be defined as the working together of researchers to achieve the common goal of producing new scientific knowledge." Respondents of a supply chain collaboration study add a culture of sharing and a partnering relationship to the definition of working together [42]. To achieve such states, a kind of proximity seems to be needed, which has traditionally been routed in the form of geographical proximity before means of travel and communication technologies reached their actual level $[8,22,53,55]$. The focus has now turned to a broader perspective encompassing several dimensions of distance today. Shearmur [50] notes that "[t]he idea that 'proximity' facilitates the acquisition of information for a firm can thus be understood from a variety of perspectives, and there is no reason to give pride of place to geographic proximity: social and other types of proximity can be effective over large distances, although geographic proximity may be more important for informal and unexpected interactions". In addition, recombining knowledge of two different sources, i.e. people or organizations, might strongly depend on technological distance. For instance, Boschma [4] sees a minimum of technological proximity to be necessary for innovative collaborations as otherwise mutual understanding is not possible. At the same time, he introduces the proximity paradox, not only for technological distance, but also for other dimensions of distance. The proximity paradox can be roughly summarized by the idea that on the one side, proximity enhances interaction and knowledge transfer and therefore eases innovative collaboration, but on the other side can create lock-in effects and therefore harm access to new ideas because people are too close and experienced with each other to discover new knowledge $[4,44]$.

The resulting and ongoing debate on different dimensions of distance consequently covers several aspects and directions. Besides the identification and determination of more distance dimensions than geographical distance, it turned out that different dimensions have an objective and directly measurable dimension as well as a subjective or perceived one. Siebdrat et al. [52] provide evidence that the influence of subjective distance is decisive for team collaboration, whereas objective distance estimates do not reveal meaningful influence. Furthermore, vom Stein and Sick [56] reveal in a preliminary qualitative study that differences between calculated and perceived technological distances are present in the examined case. While some studies conclude that about $70 \%$ of perceived geographical distance can be explained by calculated geographical distance or other respective objective indicators, others conclude that only $50 \%$ of an individual's perception of distance is explained by the calculated counterpart [12,59].

A comparable quantitative estimation of the difference between calculated and perceived technological distance will first of all add specific insights on methodological issues and contribute to debates on how to measure technological distance [3]. Secondly, it might allow for improved evaluation of collaborations in practice and thus allow for deducing adequate behavior as the awareness of such differences might prevent misinterpretation. Accepting a prominent role of technological distance in innovative collaboration activities, a better understanding of how executing researchers within a collaboration project perceive certain knowledge differences might give new insights on why some collaborations evolve or are carried out more easily than others [4].

Assessing the effect of calculated and perceived geographical distance in an academic project setting might not just replicate effects within team collaboration. Instead, it 
will give additional insights on the general meaning of geographical distance for such collaborative ventures and particularly on the type of geographical proximity required. Furthermore, reasons why differences between calculated and perceived measures exist and understanding the respective mechanisms behind them can help to better align collaborative behavior in a way that efforts to create proximity can be avoided where they are not necessary, but can be created if the necessity occurs to overcome a large calculated or perceived technological distance. As suggested by O'Grady and Lane [45], the relationship between perceived and 'real' distances is a further area worthy of research [27,45]. Thus, calculated and perceived distances will be strictly separated for the geographical and technological dimensions in this study. Particularly, it should be responded to the following research question: How are calculated technological and geographical distance related to their perceived counterparts and how do these different distance dimensions influence each other?

The remainder of this study is organized as follows. The next section covers the conceptual framework based on different theoretical perspectives and empirical evidence before relevant hypotheses are deduced. Afterwards, data and methods are described while respective results are presented and discussed in the following section. The study concludes with a concise summary of the main contributions and implications, followed by limitations and an outlook on further research.

\section{CONCEPTUAL FRAMEWORK AND HYPOTHESES}

\section{A. Distance dimensions \\ Technological distance}

In order to fully grasp the concept of technological distance, the division of knowledge into know-what, knowwhy, know-how and know-who is shortly introduced to specify areas in which knowledge differences can reside $[13,39]$. Know-what covers knowledge about facts and knowwhy about principles resulting from scientific laws, human minds or society [34]. Generally, the field as well as the depth and breadth of them can substantially vary between individuals and organizations. If they can be traced back to a common discipline or comparable similar route, such as the rationale of a new technology combining principles from different disciplines, e.g. batteries, they can be seen as basic knowledge enabling know-how [29,38]. The latter "refers to skills - i.e. the ability to do something" [34]. As this constitutes the abilities of applying know-what and knowwhy to R\&D processes as well as e.g. producing abilities of certain goods, know-how can be seen as more specialized knowledge, which nevertheless can also stem from other core areas within a general discipline $[29,38]$. Thus, it is possible that organizations or individuals have similar know-what and know-why (basic knowledge on e.g. batteries), but comparably different know-how (specialized knowledge e.g. towards the application of different cell materials). Know- who finally refers to the knowledge about who knows what (including know-what, know-why and know- how) and the ability to retrieve it from the resulting network of actors [34]. The network and thus the related knowledge obviously can strongly differ between two collaboration partners and probably especially open up access to new knowledge as indicated by the concept of structural holes $[1,7,58]$. The extent of absorptive capacity however might be less influenced by such differences as it seems to be only relevant as soon as a certain need for the collaboration or the partner is identified on their existing knowledge bases comprising the other three types of knowledge.

The inverted u-shaped relationship between technological distance and innovation collaboration success is primarily explained by absorptive capacity and the novelty value included in the partner's knowledge $[56,57]$. A motivational factor, which can also be traced back to technological distance might further influence this relationship and therefore is explained in the following. On the firm level, Hinds and Pfeffer [30] identify several motivational incentives and disincentives for knowledge sharing. Competition as a disincentive can obviously be transferred to the collaboration context and related to technological distance and the NIH-syndrome [29]. Sharing knowledge includes the risk of losing an expert status. It can enable the receiver to perform similar or even better than the sender. In that case, the sender would lose his expert status. The fear on that can prevent him from sharing knowledge, especially if he does not expect adequate returns [30]. This might especially be the case if low technological distance is involved. E.g. if two scientists work in a similar field (similar know-what and know-why) and the know-how of the sender enables the receiver to find a better or faster solution to a scientific problem, the receiver might receive the glory (e.g. being first author in a publication) and not the sender. If technological distance is comparably high, the receiver might especially fear that his expert status will be attacked as completely different know-how or even know-what or know-why might have the ability to replace his know-how and thus makes his expertise obsolete [29]. Even if he would be able to keep up with this development, his work routine would at least be influenced. The general tendency to keep a state or routine to increase certainty is seen as one prerequisite of the notinvented-here (NIH) syndrome as external knowledge can increase personal uncertainty $[37,49]$. A perceived expert status of the receiver might further impede him to admit nonunderstanding and further asking [29]. As low technological distance should generally lead to understanding, this phenomenon might especially occur if high technological distance is in place. However, as soon as an expert e.g. might not be able to articulate his knowledge adequately, a receiver with comparable knowledge might more than ever feel intimidated to ask. In this line, the knowledge receiver might not just be hindered to understand and access but also to appreciate external knowledge [11]. Status hierarchies represent another motivational factor, which might reinforce 


\section{Proceedings of PICMET '16: Technology Management for Social Innovation}

this negative influence of technological distance on knowledge sharing. If e.g. a Ph.D. student feels intimidated to ask a hierarchically superior person (e.g. another research group's professor) for advice [30]. The other way around, some hierarchically superior people might refuse the application from a person with a lower status to keep their hierarchical superiority. Again, the fear of being ridiculed might be especially high at very low and very high levels of technological distance.

The probably most differentiating characteristic between calculated and perceived distance is expressed by Wilson et al. [59]: '[U]nlike 'objective distance,' which can be observed or calculated by others, perceived proximity is known only to the focal person. Perceptions of proximity are naturally asymmetric; for example, a treasury analyst can perceive the account manager as proximal without the account manager having similar perceptions of the analyst.". Information on a certain collaboration partner like the chemical compound a research group works on or a specific cell setup of another research group add to the cognitive component as one driver of the perception of technological distance. Besides such objective categorizations constituting a cognitive component, e.g. measurable by publication- or patent-data, perceived technological distance might also have as an affective component $[18,32,35,40]$. The more familiar one gets with a research group's work and knowledge and the people performing it, the more technological proximate one may feel towards them. Communication, irrespective of its form, should also reduce the feeling of technological distance as more knowledge of the partner will be presented and its accessibility will be eased by regular and intensive communication [41]. Commonalities might as well be identified with respect to knowledge and work as with respect to other aspects of life of the group participants increasing familiarity and thus the perception of technological proximity.

\section{Geographical distance}

Geographical distance can be expressed as an absolute kilometric value that can be calculated by everyone who is knowledgeable on the two locations which should be compared and therefore is a continuous measure. Following that, it might overlook certain aspects on the accessibility of a partner, which are further determined by means of transportation and communication technologies [10,54,55]. The logic behind this is that individuals and organizations in particular evaluate time and costs to create a certain contact $[23,43]$. Information and communication technologies (ICT) offer the opportunity to substitute traveling and resulting face-to-face contact, which leads to large savings of time and costs if geographical distance is high [54]. As respective technologies are still not seen to be a fully substitute of faceto-face contacts, travel time and costs show a high influence when geographical distance has to be overcome [23]. Besides travel time and costs, further temporal effects, particularly different time zones [46], influence the magnitude of geographical or functional distance as Coenen et al. [10] phrase it to highlight the argument of accessibility.

On the team level, the configurationally dispersion of team members is emphasized as an additional influencing factor if more than two individuals are involved and especially dispersed over more than two locations [46,47]. Considering a mean value of geographical distance is easily misleading as the complexity of coordination rises with an increased number of people and locations [15]. The mean value might further strongly under- or overestimate the geographical distance and thus the travel effort for individuals who are located especially far or close in comparison to the other team members [46]. Varying meeting locations due to the state of the project and resulting location necessities or the organization premises can also result in different and changing efforts for the individual team members to attend them [31].

Time and costs of traveling as well as team member dispersion are nevertheless real quantities under certain assumptions like a specific mean of transport at defined costs. Thus, an objective representation of geographically or naturally given access advantages or disadvantages, including transport infrastructure, is achieved by including them in the definition of geographical distance. The assumption of equivalent access to different means of transport at the same costs and time does only conditionally hold true, especially in the short-run and in an individual's perception. Although Torre and Rallet [55] explicitly include the perceptional aspect of geographical proximity in their definition, they finally consider it as a physical space data. Others directly limit their definition to time and cost aspects $[10,43,52]$. The latter e.g. name team members' separation by time zones, travel time between locations or the ability of the actors to arrange face-to-face meetings in the duration of one working day as relevant definitions and quantities [43,52]. Boschma [4], in contrast, does not entirely elaborate what aspects are included in the relative meaning of geographical distance. Some aspects of the perceived part of geographical distance are included in other dimensions of distance like the adoption of similar mental maps in organizational distance. As Moodysson and Jonsson [43] interpret it in a similar way, relative meaning referring to time and cost aspects should be kept in the definition in accordance with Siebdrat et al. [52], but is explicitly limited to such objectively measurable characteristics here.

To the factors, that drive the perception of geographical distance besides measureable facts, belong individual aspects like age, profession or the propensity to take risk [12, 55]. An-open minded person, who is keen on new experiences and has already experience with geographically dispersed work, e.g. might encounter a comparable large geographical distance more an interesting experience than a threat and gets more easily involved into other modes of communication than face-to-face meeting. In turn, this reduces the perception of geographical distance that has to be overcome [59]. Another group of influencing factors results from relational 


\section{Proceedings of PICMET '16: Technology Management for Social Innovation}

aspects. Communication frequency, interactivity and depth between two individuals are seen as one factor that influences the perception of geographical distance [59]. The more often and intensive contacts between involved parties are, the more should the perception of a certain distance decline due to increased availability of information. Although the transfer of these information is mediated and does not include face-toface communication [6], it "increas[es] cognitive salience, reduc[es] uncertainty and envision[s] the other's context" [59]. Thus, communication creates awareness and familiarity, including predictability and understanding of each other, which then creates a feeling of geographical proximity as access to the partner and his activities seems easier. By that, interaction and thus collaboration might become a matter of course. Identified commonalities, like the same nationality, common hobbies or shared experiences, represent other aspects, which basically follow the same logic of reducing the perception of geographical distance by familiarity [14]. Dense network structures and structural assurance within an organization or collaboration, e.g. resulting from standard processes, promises or contracts, follow the same principles of enhancing communication, familiarity and accessibility leading to reduced perceptions of geographical distance [59].

The overview on empirical evidence as well as the discussion within the theoretical distance concept itself reconfirms further need for clarification of the influence and interaction of different distance dimensions. To satisfy this need, a hypotheses concept will be developed in the following.

\section{B. Hypothesis development}

Although some differences between calculated and perceived technological distance have been found, the logic underlying the used measures that common knowledge manifests in addressing the same journals or same topics suggests a strong positive relationship between them. Comparable quantitative results exist for other calculated and perceived distance dimensions [12,27,52]. Following the assumption that the calculated one presents an objective and exogenous value driving the perceived one, the following hypothesis $(\mathrm{H})$ is set up:

H1: Calculated technological distance has a positive effect on perceived technological distance.

Considering the change logic of geographical distance (movement), a positive relationship between calculated technological distance and perceived geographical distance is suggested [41]. Within the project, it can be assumed that no permanent movements particularly devoted to one dyad occur, but that technologically more proximate partners meet more often at conferences or workshops. Although Hansen [28] finds a substitution mechanism between geographical and technological distance, this mechanism seems to be of minor importance here because a common organizational framework is given by the project set-up, which already considers each partner's location e.g. by respective travel budgets and focuses on a specific region. Thus, especially as the influence on the perception rather than the objective geographical distance is considered, temporary episodes of decreased geographical distance might be responsible for a positive influence of calculated technological distance on perceived geographical distance.

H2: Calculated technological distance has a positive effect on perceived geographical distance.

Generally, increased calculated geographical distance comes along with increased travel times and costs and therefore influences the perception of geographical distance. Although Coshall and Potter [12] analysis limits this influence to $50 \%$ of variance explained, the overall positive relationship is undoubted and therefore hypothesized.

H3: Calculated geographical distance has a positive effect on perceived geographical distance.

Knowledge spillovers and learning are more likely to occur in case of geographical proximity between individual research groups. Hansen [28] and Broekel [5] only find a substitution mechanism, which would give an explanation for a non-significant or a negative effect. However, it is given precedence to the change logic of learning by geographical proximity, supported by interview insights $[5,28,56]$.

H4: Calculated geographical distance has a positive effect on perceived technological distance.

Learning might also be more prevailing from a perceived rather than a calculated geographical point of view as it again at least reflects whether awareness of geographical proximity and thus knowledge sources exists.

H5: Perceived geographical distance has a positive effect on perceived technological distance.

Following the logic that perceived geographical distance or proximity more clearly reflects realized accessibility of other organizations and resulting knowledge sources, it should facilitate the influence of calculated geographical distance on learning.

H6: Perceived geographical distance mediates the effect between calculated geographical distance and perceived technological distance.

Furthermore, given the positive influence of calculated technological distance on perceived geographical distance, which implies better reachability and thus learning opportunities, at least a partial mediation effect of perceived geographical distance between calculated and perceived technological distance is hypothesized.

H7: Perceived geographical distance mediates the effect between calculated technological distance and perceived technological distance.

The resulting interaction model of distance dimensions is displayed in Fig. 1, containing the relationship between the 


\section{Proceedings of PICMET '16: Technology Management for Social Innovation}

two objectively calculated constructs of geographical and technological distance and their perceived counterparts as well as perceived technological distance as the hierarchical highest dependent variable which should be finally explained by all other distance dimensions.

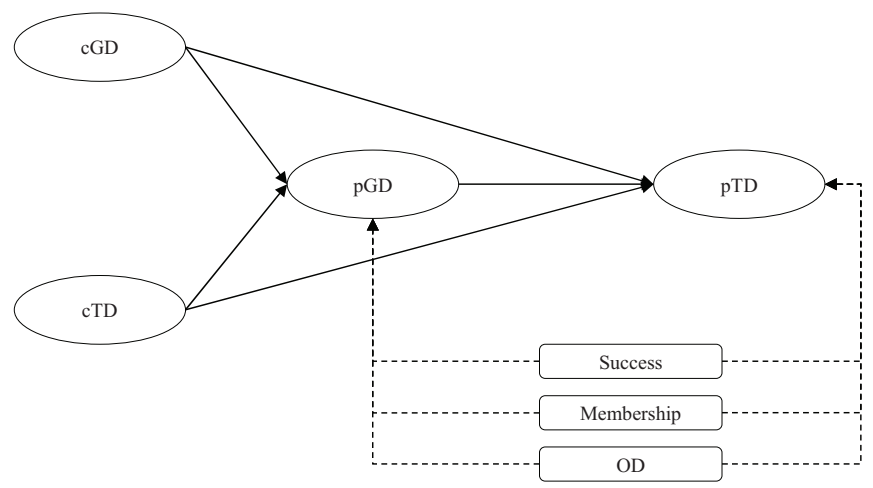

Figure 1: Interaction model of calculated and perceived technological and geographical distance.

\section{DATA AND METHODS}

\section{A. Data collection approach}

The battery research project considered here consists of eleven academic research groups from four German universities or research institutes and one Japanese university implicating ten possible dyadic collaborations for each project partner. Consequently, 110 possible asymmetric cases result in total. The data collection is based on an online survey within the project. To receive the answers, a key informant approach is used that asks for a person that is knowledgeable of the phenomenon under study, able and willing to communicate with the executing researcher $[9,33]$. This approach is further seen as convenient for the participants because an e-mail distribution via an included link ensures easy access and the point in time of completion can be chosen individually by each participant [19,51]. At the same time, costs and time effort are kept in a convenient and acceptable range for the executing researcher [17]. Nonetheless, answering all questions for all ten partners seems to be a time consuming task. Therefore, the cases have been split into sets of three cases constituting one questionnaire. As the availability of more than three key informants does not seem to be likely in most cases, the eleventh project partner, who might not interact as regularly with all project partners due to its location in Japan, is introduced as a voluntary option at the end of each questionnaire.

\section{B. Measures}

Calculated technological distance is measured via a publication-based approach using the min-complement distance [56,57]. A detailed discussion of different distance measures can be found in vom Stein et al. [57]. As no specific measures for perceived technological distance are known in literature so far, their operationalization is based on indicators measuring technological distance used in surveys as these should capture participants' estimation or perception on the topics raised $[17,26]$. The scale developed by Cummings and Teng [46] for knowledge distance is used here and adapted to a two partner's relationship context. As a main purpose of this study is to detect influences that drive the perception and especially differences of perception and objective calculations, additional indicators used in other studies or mentioned during expert interviews are added in order to allow for additional explanations [56]. Following existing items, most of them are framed in terms of proximity but have been recoded to terms of distance by inverting the Likert-scale before analysis to display the same direction as calculated distance dimensions.

Calculated geographical distance is defined as the distance between the respective working places. A research group's location is generally determined by its address as current route planners and distance calculators use this information as standard input format. The website entfernungenberechnen.com is used for beeline calculation. It provides estimations in kilometers and miles with two decimal places. The latter might be of importance to differentiate between the nearly co-located research groups of one university or research center and those being real neighbors. For four research groups, another approach is needed because they are located within a research center, whose exact addresses are not available at entfernungenberechnen.com or other navigation tools due to its non-public status. The not to scale visitor map of the research center is used to identify the locations as precisely as possible within Google Maps to receive an approximation of geographic coordinates, which are then fed into the calculation tool instead of the addresses [25]. Following comparable approaches of geographical distance estimations, the derived geographical distances are log-transformed afterwards [52]. The operationalization of perceived geographical distance is based on Hoegl and Proserpio's [31] measure for subjective distance between team members. As different research groups are considered here instead of individuals within one team, two of the items seem to be inappropriate for most of the investigated collaboration pairs and are therefore eliminated. The remaining two items are adapted to investigate perceived geographical distance between the different project partners. The first one asks if partners are located too far away to move the project along smoothly while the second one asks if partners work nearby, so that they could visit each other without much effort.

A primary source of variance in the perceived distance measures not explainable by the supposed independent variables, which should be controlled for, may result from other distance dimensions. Therefore, organizational distance (OD) is used as one control variable to divide whether both partners have a university or a research institute's background or if one partner has a university and the other a research institute's background resulting in a dummy variable $[16,20]$. 


\section{Proceedings of PICMET '16: Technology Management for Social Innovation}

This separation is based on an existing broader approach distinguishing between academic and non-academic partners whereby universities and other research institutes are grouped as academic [20]. As the adaption to the university and research institute's difference consequently might be of less importance, a minor influence can again be deduced which nevertheless is controlled for. A group's general attitude towards and experiences within the project might further influence the perception of distances towards the partners. As being part of the project usually is related to certain research aims, an indicator of project performance for the individual research group (success) is introduced to control for variance resulting from positive or negative experience with the project. As a third control variable (membership) a dummy variable is introduced capturing whether the participant started working in the research group before the project started or afterwards to control for variance which might either result from a lack of familiarity with the respective research group or from a specific identification to the project. The latter might e.g. occur if someone is directly employed for the project and can focus on respective tasks rather than if he is carrying them out in addition to already existing tasks in other projects.

\section{RESULTS AND DISCUSSION}

In total, 25 questionnaires were completed resulting in 79 cases as four participants answered the voluntary fourth case. $72 \%$ of the possible asymmetric cases are finally covered within the data and constitute the distance interaction data set or model in subsequent analyses.

The scientific background of survey participants comprises four different disciplines, which are all associated to battery research. $48 \%$ of the participants show a chemical background, while engineering, material science and physics are represented by $16 \%, 20 \%$, and $16 \%$ of the participants, respectively. As it has to be kept in mind that some of the 25 questionnaires could have been answered by one person, an overestimation of one discipline is not unlikely. Nevertheless, it confirms the interdisciplinary nature of the project considered. Even more differences can be found on a lower hierarchy level of disciplines. As a couple of differences results in single cases, quantitative data is only provided for aggregated major discipline level. Differences among the chemists, especially between inorganic and physical chemists, as well as different types of engineers are present in the survey and thus in the project.

Large research projects, as the one considered here, usually comprise funds not only for material resources but especially for human resources. The fluctuation of young researchers is usually quite high as e.g. the duration of Ph.D. studies lies around four years and is tried to be limited to three years. Thus, it is likely that new research group members are particularly hired for or during a project of that size. This is confirmed by observing the participants of the survey whereof $48 \%$ have worked in the research group before the project started while $52 \%$ joined later on.

We first analyzed a base model comprising the influence of calculated geographical and technological distance on perceived technological distance as well as the control variables (see Fig 2).

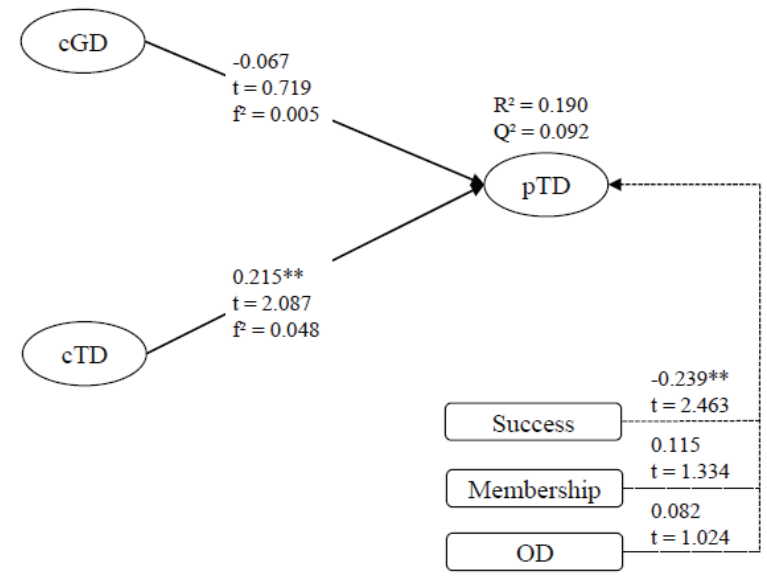

Figure 2: Base model testing the influence of calculated technological and geographical distance on perceived technological distance.

Within this base model, calculated technological distance reveals a significant positive impact on perceived technological distance, lending support to hypothesis 1 . No support is given for hypothesis 4, as the path coefficient between calculated geographical and perceived technological distance is slightly negative and not significant. The direct effect of calculated geographical distance on perceived technological distance is not significant. The $\mathrm{R}^{2}$-value of 0.190 seems to be improvable as less than $20 \%$ of variance of perceived technological distance is explained. Perceived geographical distance is introduced next and the full model is depicted in Fig. 3.

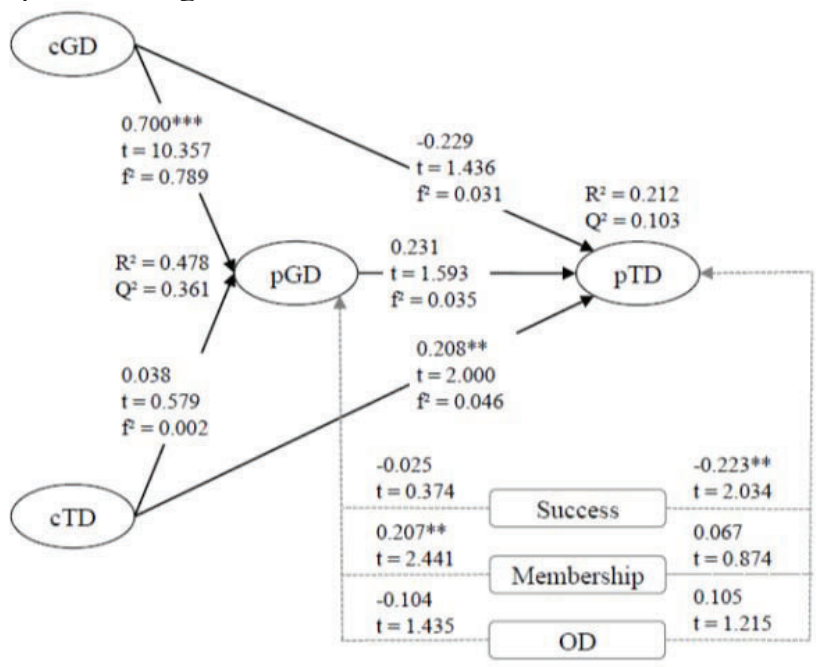

Figure 3: Path model of calculated and perceived technological and geographical distance. 
When perceived geographical distance is included in the model, the relationship between calculated and perceived technological distance stays positive and significant adding further support to hypothesis 1 . In contrast to that, no support is found for hypothesis 2 as the path coefficient between calculated technological distance and perceived geographical distance is comparably small and not significant. A significant direct effect between the independent variable (cTD) and the mediator (pGD) is a necessary condition for a mediation effect and as no considerable reduction of the path coefficient between calculated and perceived technological distance occurs. Furthermore, the direct effect of perceived geographical distance on perceived technological distance is not significant, which first of all indicates rejection of hypothesis 5. Secondly, this substantiates the rejection of hypothesis 6 which hypothesized perceived geographical distance to be a mediator between calculated and perceived technological distance. Thirdly, the hypothesized mediation effect between calculated geographical distance and perceived technological distance by perceived geographical distance (hypothesis 7) also has to be rejected. However, strong support is indicated for hypothesis 3 as the direct effect between calculated and perceived geographical distance is positive and highly significant. The decrease of the path coefficient between calculated geographical distance and perceived technological distance from nearly zero (0.067 ) to -0.229 might hint at a suppression effect, but the path coefficient is not significant. The $\mathrm{R}^{2}$-value of perceived technological distance increases slightly after adding perceived geographical distance to 0.212 . The results of hypotheses testing are summarized in Table 1.

Calculated technological distance only reveals a significant positive influence on its perceived counterpart. This first of all confirms that calculated and perceived estimates of the technological distance dimension do not measure completely different things. However, the $\mathrm{R}^{2}$-value of perceived technological distance is only 0.19 in the distance interaction model including calculated geographical and technological distance as well as the control variables. The simplest model only including calculated and perceived technological distance reveals that only $9.1 \%$ of the latter's variance are explained by its calculated counterpart as well as only weak predictive relevance of calculated technological distance on its perceived counterpart is revealed. Irrespective of other factors that are included in the model, this confirms that the perception of technological distance deviates from publication-based calculated ones. Thus, comparability of respective studies operationalizing technological distance in different ways cannot carelessly be undertaken.

Other external and more or less objective factors might further add to the explanation of perceived technological distance, which are not covered in publication-based calculated technological distance. A first one, scientific background, has already been tested in a group comparison and by dummy coded variables. Although only the material science dummy coded variable reveals a significant influence on perceived technological distance if all dummy coded variables are included at the same time, the $\mathrm{R}^{2}$-value of perceived technological distance clearly increases then. Thus, scientific background adds to the explanation of perceived technological distance, which might also explain the less pronounced effect of calculated technological distance. Some shared variance between calculated technological distance causing that effect seems to be at least logical as the separation into participants' background removes heterogeneity among them but not among the academic background of the different research groups, whose knowledge or behavior they have to evaluate. Therefore, as long as each research group is still related to a particular scientific field resulting in respective publications, an interrelation of the two indicators should remain. Other objective indicators driving perceived technological distance might be conference attendance, projects a research group is involved in, other collaboration partners, institutional affiliation within a university, lecture topics or applied equipment in research activities. In all cases, it can be assumed that revealed similarity by e.g. joint conference attendance or utilization of the same analytical instruments, might increase the perception of proximity while revealed differences by e.g. being affiliated to different scientific departments as inorganic chemistry and electrical engineering might increase the perception of distance. Applied equipment is included in the perceived technological distance scale by the similar resource item. In contrast to some expectations, it aligns well with the other indicators of perception. Therefore, it seems even more reasonable that an obvious evaluation of such differences could add to explain perceived technological distance.

TABLE 1: SUMMARY OF THE RESULTS OF HYPOTHESES TESTING BETWEEN DIFFERENT DISTANCE DIMENSIONS.

\begin{tabular}{llll}
\hline & Exogenous variable/ mediator & $\begin{array}{l}\text { Direction / } \\
\text { mediation }\end{array}$ & Endogenous variable/ mediated relationship \\
\hline H1 & Calculated technological distance (cTD) & + & Perceived technological distance (pTD) \\
\hline H2 & & + & Perceived geographical distance (pGD) \\
\hline H3 & Calculated geographical distance (cGD) & + & Perceived geographical distance (pGD) \\
\hline H4 & & + & Perceived technological distance (pTD) \\
\hline H5 & Perceived geographical distance (pGD) & + & Perceived technological distance (pTD) \\
\hline H6 & $\mathrm{m}$ & $\begin{array}{l}\text { Calculated geographical and perceived technological } \\
\text { distance (cGD and pTD) }\end{array}$ \\
\hline H7 & $\mathrm{m}$ & $\begin{array}{l}\text { Calculated and perceived technological distance (cTD } \\
\text { and pTD) }\end{array}$ \\
\hline
\end{tabular}


The whole network of a research group has to be mentioned to get an impression of the availability of other named obvious indicators that might drive the perception of technological distance. While the existence of the same or similar official collaboration partners might be objectively observable, this might not hold true for other informal contacts. Complementarities in research activities or the research focus on e.g. a single element of the battery like polymer electrolytes or the entire cell might further drive perceived technological distance. In accordance with findings for differences of calculated and perceived geographical distance, other personal characteristics than scientific background, like age, risk aversion or open-mindedness might drive perceived technological distance as well [12,55]. Particularly age might become a stronger influence factor on the perception of technological and geographical distance due the so-called digital natives, who are about to start their professional careers in academia and industry. The young generation of scientist and engineers, who have been using internet, tablets and smartphones ever since, might perceive geographical distance as less important because they are already used to communicate online via video conferences, chats, mails and voice over IP, e.g. Skype. In this respect, digital natives might tend to perceive less geographical distance when working at different locations (e.g. project consortia) or even in different countries (not at all uncommon, e.g. for EU-funded projects). The same holds true for technological distance since learning and especially life-long learning to decrease technological distance are natural and self-evident for the younger generation. In addition, information and knowledge, the groundwork of learning, are much more at hand and easily accessible for digital natives. On the other hand, the present study covers academic working groups where learning and new knowledge creation are core competences, so that perceptions may not vary that widely here. To derive more detailed explanations concerning differing perceptions of younger generations, we would encourage further research to include variables that allow controlling for age or familiarity with digital technologies.

Besides these factors the timely development or dynamism of calculated and perceived technological distance has to be considered as explanation. The aggregation of a research group's publications to approximate calculated technological distance can cover several years, while the estimation of perceived technological distance is surveyed at the actual point in time. It seems to be reasonable that all knowledge stays at least to a certain extent within a research group and that aggregation therefore creates more general and robust estimations [3]. In contrast to that, the collaborating partner might be more focused on recent activities and knowledge relevant to the collaboration when evaluating the respective knowledge base.

In contrast, calculated technological distance does not reveal any significant influence on perceived geographical distance. A positive relationship towards perceived geographical distance was assumed due to better accessibility at e.g. conferences or workshops. While this might still hold true in a broader context, several reasons why it does not hold in the project context evaluated here can be found. First of all, the project is on a common research topic, batteries, which makes attendance of the same conferences by all participants a lot more likely than in comparing research groups from completely unrelated fields especially as several conferences particularly devoted to batteries are held. Secondly, the introduced examples of facilitated temporary co-location might be outbalanced by regular project meetings, which are attended every half a year by all project partners. Thirdly, accessibility of partners could already be considered when the project was set up and therefore might have been given without further movement encouraged by calculated technological proximity.

For calculated geographical distance, comparable findings as for calculated technological distance occur, which reveal a significant and positive effect on its perceived counterpart. Before reasons for the insignificance of other path coefficients from calculated geographical distance are discussed, a look on the $\mathrm{R}^{2}$-value of perceived geographical distance is worthwhile. Less than $50 \%$ of perceived geographical distance's variance is explained, although calculated geographical distance reveals strong predictive relevance. A further test, in which only calculated geographical distance is modeled on perceived geographical distance, confirms this with an $\mathrm{R}^{2}$-value of 0.427 based on the whole distance data set. This is in line with the estimation of Coshall and Potter [12], who find less than $50 \%$ of variance to be explained by objective geographical distance.

For perceived geographical distance, the positive direct effect has to be rejected for perceived technological distance. The non-significant path towards perceived technological distance hints at a stronger impact of social distance on perceived technological distance in line with the argumentation above and the notion of Boschma [4] of geographical distance to potentially "play a complementary role in building and strengthening social [and other] proximity", but not to be necessary for knowledge transfer. Ganesan et al. [21] state that "relational ties moderate several linkages in the path between geographic proximity and new product development". They further confirm that geographical distance negatively affects face-to-face contact and that this phenomenon is more pronounced for strong ties, i.e. for social proximity, while e-mail communication is not affected by geographical distance.

Turning back to the relationship between perceived geographical and technological distance, there is less or even no negative correlation in contrast to their calculated counterparts. This might hint at a general mechanism of accessibility and familiarity by perceived geographical distance fostering learning to be in place here, too. This means that the substitution mechanism would lead to successful learning or movement, which reduces at least the perceived distance dimension of a respective large calculated 
distance dimension. This argumentation would also be in line with the suggested mediating function of perceived geographical distance. Seeing the substitution and learning effect as two functions competing over time, respective nonsignificance might be well explainable here, too. Another reason might be that even perceived geographical distance is not sufficient to directly cause learning indicated by a significant indirect effect via perceived social distance, at least in the distance interaction model. Besides the above mentioned reasons for insignificance of the relationship between calculated technological distance and perceived geographical distance, mediation might not occur as judgment of objective knowledge differences might generally prevail over spatial accessibility.

\section{CONCLUSION AND OUTLOOK}

The research question focuses on the interaction between calculated and perceived distance dimensions. Firstly, a positive relationship between the two calculated distance dimensions, technological and geographical distance, and their perceived counterparts is confirmed. However, respective measures do by far not entirely overlap. For technological distance, less than $10 \%$ of perceived technological distance's variance is explained while for geographical distance, the fitting is better as a bit less than $50 \%$ of the perceived geographical distance's variance is explained, which is in line with former studies in different fields. Thus, calculated and perceived distances are positively interrelated, but the perceived ones are further influenced by other factors. Other objective criteria like scientific background for technological distance or shortest travel time for geographical distance might belong to such factors as well as affective influences.

These results contribute to several aspects of distance research. The small explained variance of perceived technological distance by calculated technological distance confirms that the two operationalizations of the construct technological distance differ substantially. Thus, operationalization and interpretation of technological distance as a construct should be distinguished into a calculated or objective and perceived or subjective one. Hansen [28] states that "other studies of proximity and innovation are based on data on scientific co-publications or EU-funded projects $[2,48]$, the interview approach allows an operationalization of the proximity categories which is closer to Boschma's framework" [28]. He relates the differences to the level of definition. Although definitions that are better displayed by one or the other operationalization might exist, such a differentiation seems not to be consequently pursued in the literature [4,24,28]. Therefore, a respective differentiation from the definition to the operationalization and interpretation should be seeked and broadly applied. At least, as many factors that can be identified to be responsible for respective differences as possible should be taken into account by either controlling them within an empirical model or when interpreting respective results.

Another approach might be an agglomerated measure of technological distance, which ideally would cover calculated and perceived indicators. Due to the difficulties of matching such data, this might not always be feasible, but at least partly achievable by e.g. combining objective facts like scientific background or industry background of key informants, research groups or companies and Likert-scale accessible items in questionnaires. When relying on publicly accessible data, a combination of publication or/and patent data with respective indicators like scientific background or attended conferences' topics might at least better align the publicationbased and perceived technological distance operationalization if no strict comparison or definitional separation can be achieved.

For geographical distance, respective indicators are at least discussed in terms of multiple objective indicators $[46,52]$. As they still reveal some differences with perceived geographical distance, the two dimensions also should be considered from a definitional and operationalizing point without ignoring its interrelations [52]. Consequently, taking at least possible differences between calculated and perceived geographical distance into account when enhancing theory and interpreting empirical results seems to be vital for future research. In a similar way, other distance dimensions might also be approached as theoretical considerations at least indicated that respective differences might be present for all distance dimensions.

Towards the question whether different distance dimensions substitute and bridge or overlap and co-evolve, a differentiation between the calculated and perceived dimensions evolves within this study. While the calculated dimensions, technological and geographical, hint at a substitution or bridging mechanism, a certain overlap or coevolvement is present for the perceived dimensions. Therefore, the distinction between calculated and perceived dimensions should especially be taken into account when investigating change mechanisms of different distance dimensions. Direct comparisons can further add to understand (timely) developments. Respective mechanisms should be included in distance studies to improve the understanding of the interrelationships as well as overall understanding as the influence of a single distance dimension otherwise might be misleading. It might e.g. be different in cases where a certain proximity dimension functions as a substituting or as an overlapping and thus rein-forcing factor. This suggests that particular care has to be taken here and analytical routes have to be improved to ensure uncovering of distorting effects.

The setting of the study at hand has a variety of advantages, like the improved accessibility of study participants due to the authors' inclusion into the project and delivers meaningful results in distance research as well as valuable theoretical and practical implications. However, it also brings forth some limitations. The project scope already provides a pre-selection of research groups and respective 


\section{Proceedings of PICMET '16: Technology Management for Social Innovation}

dyads. Although certain heterogeneity in the different distance dimensions and especially calculated technological distance at least on a specialized knowledge level is present, the pre-selection of partners limits the generalizability beyond a project scope e.g. on a local cluster. A case study is done on project level, which obviously has to be confirmed for other cases or projects. Nevertheless, collaborations are generally not entered without a thorough selection and consideration of respective partners. Thus, the limitation might be especially pronounced for discussions and implications where a positive influence of the project scope is assumed like the positive influence of knowledge heterogeneity for partner selection with certain potential of knowledge novelty. Consequently, substantiating respective findings and implications on the multi-partner project level while taking into account specific dyadic or work-package related collaborations is necessary. Therefore, replication and extension of this study in other multi-partner projects e.g. focusing on other research topics or including partners who narrow or expand heterogeneity along certain distance dimensions, is recommended for further research.

The inclusion of further distance dimensions in future studies also belongs to such investigations. The inclusion of e.g. industrial companies in respective projects asks for a more thorough investigation of organizational distance, in a calculated as well as in a perceived form. The same holds true for cultural distance. For projects, in which more different cultures or nations are represented, employing presented constructs of psychic distance, in its meaning of perceived cultural distance and cultural distance as objectively calculated distance at the same time would be vital to get a complete picture of distance dimensions.

\section{REFERENCES}

[1] Ahuja, G., "Collaboration Networks, Structural Holes, and Innovation: A Longitudinal Study," Administrative Science Quarterly, vol. 45, pp. 425-455, 2000.

[2] Balland, P., "Proximity and the Evolution of Collaboration Networks: Evidence from Research and Development Projects within the Global Navigation Satellite System (GNSS) Industry," Regional Studies, vol. 46, pp. 741-756, 2012.

[3] Benner, M. and J. Waldfogel, "Close to You? Bias and Precision in Patent-Based Measures of Technological Proximity," Research Policy, vol. 37, pp. 1556-1567, 2008.

[4] Boschma, R., "Proximity and Innovation: A Critical Assessment," Regional Studies, vol. 39, pp. 61-74, 2005.

[5] Broekel, T., "The Co-Evolution of Proximities - A Network Level Study," Regional Studies, vol. 49, pp. 921-935, 2015.

[6] Burgoon, J. K.; J. A. Bonito; A. J. Ramirez; N. E. Dunbar; K. Kam and J. Fischer, "Testing the Interactivity Principle: Effects of Mediation, Propinquity, and Verbal and Nonverbal Modalities in Interpersonal Interaction," Journal of Communication, vol. 52, pp. 657-677, 2002.

[7] Burt, R. S., Neighbor Networks: Competitive Advantage Local and Personal, Oxford: OUP Oxford, 2009.

[8] Cairncross, F., "The Death of Distance: How the Communications Revolution is Changing our Lives," Harvard Business School Press Books, 2001.

[9] Campbell, D. T., "The Informant in Quantitative Research," American Journal of Sociology, vol. 60, pp. 339-342, 1955.
[10] Coenen, L.; J. Moodysson and B. T. Asheim, "Nodes, Networks and Proximities: On the Knowledge Dynamics of the Medicon Valley Biotech Cluster," European Planning Studies, vol. 12, pp. 1003-1018, 2004.

[11] Cohen, W. M. and D. A. Levinthal, "Absorptive Capacity: A New Perspective on Learning and Innovation," Administrative Science Quarterly, vol. 35, pp. 128-152, 1990.

[12] Coshall, J. T. and R. B. Potter, "Social Psychological Variations in the Distance Cognitions of Urban Consumers in Britain," Journal of Social Psychology, vol. 127, pp. 611-618, 1987.

[13] Cowan, R.; P. A. David and D. Foray, "The Explicit Economics of Knowledge Codification and Tacitness," Industrial and Corporate Change, vol. 9, pp. 211-253, 2000.

[14] Cramton, C. D., "The Mutual Knowledge Problem and its Consequences for Dispersed Collaboration," Organization Science, vol. 12, pp. 346-371, 2001.

[15] Cramton, C. D. and S. S. Webber, "Relationships among Geographic Dispersion, Team Processes, and Effectiveness in Software Development Work Teams," Journal of Business Research, vol. 58, pp. 758-765, 2005.

[16] Cunningham, S. W. and C. Werker, "Proximity and Collaboration in European Nanotechnology," Papers in Regional Science, vol. 91, pp. 723-742, 2012.

[17] Dillman, D. A.; J. D. Smyth and L. M. Christian, Internet, Mail, and Mixed-Mode Surveys: The Tailored Design Method. (3rd ed), Hoboken, NJ, US: John Wiley \& Sons Inc, 2009.

[18] Eagly, A. H.; A. Mladinic and S. Otto, "Cognitive and Affective Bases of Attitudes Toward Social Groups and Social Policies," Journal of Experimental Social Psychology, vol. 30, pp. 113-137, 1994.

[19] Evans, J. R. and A. Mathur, "The Value of Online Surveys," Internet Research, vol. 15, pp. 195-219, 2005.

[20] Frenken, K.; R. Ponds and F. van Oort, "The Citation Impact of Research Collaboration in Science-Based Industries: A SpatialInstitutional Analysis," Papers in Regional Science, vol. 89, pp. 351$371,2010$.

[21] Ganesan, S.; A. J. Malter and A. Rindfleisch, "Does Distance Still Matter? Geographic Proximity and New Product Development," Journal of Marketing, vol. 69, pp. 44-60, 2005.

[22] Gassmann, O., "Opening Up the Innovation Process: Towards an Agenda," R\&D Management, vol. 36, pp. 223-228, 2006.

[23] Gilly, J. and F. Wallet, "Forms of Proximity, Local Governance and the Dynamics of Local Economic Spaces: The Case of Industrial Conversion Processes," International Journal of Urban and Regional Research, vol. 25, pp. 553-570, 2001.

[24] Gilsing, V.; B. Nooteboom; W. Vanhaverbeke; G. Duysters and d. O. van, "Network Embeddedness and the Exploration of Novel Technologies: Technological Distance, Betweenness Centrality and Density," Research Policy, vol. 37, pp. 1717-1731, 2008.

[25] Google and GeoBasis-DE/BKG, "Google Maps. https://www.Google.De/Maps. Last Access: 12/21/2014," 2014.

[26] Gosling, S. D.; S. Vazire; S. Srivastava and O. P. John, "Should we Trust Web-Based Studies? A Comparative Analysis of Six Preconceptions about Internet Questionnaires," The American Psychologist, vol. 59, pp. 93-104, 2004.

[27] Håkanson, L. and B. Ambos, "The Antecedents of Psychic Distance," Journal of International Management, vol. 16, pp. 195-210, 2010.

[28] Hansen, T., "Substitution Or Overlap? the Relations between Geographical and Non-Spatial Proximity Dimensions in Collaborative Innovation Projects," Regional Studies, vol. 49, pp. 1672-1684, 2015.

[29] Hartig, J., Learning and Innovation @ a Distance : An Empirical Investigation into the Benefits and Liabilities of Different Forms of Distance on Interactive Learning and Novelty Creation in German Biotechnology SMEs, Gabler, 2011.

[30] Hinds, P. J. and J. Pfeffer, "Why Organizations Don't 'Know What They Know': Cognitive and Motivational Factors Affecting the Transfer of Expertise," Ackerman, M.S.; Pipek, V. et al., Cambridge and London: MIT Press, 2003.

[31] Hoegl, M. and L. Proserpio, "Team Member Proximity and Teamwork in Innovative Projects," Research Policy, vol. 33, pp. 1153-1165, 2004. 


\section{Proceedings of PICMET '16: Technology Management for Social Innovation}

[32] Huskinson, T. L. H. and G. Haddock, "Individual Differences in Attitude Structure: Variance in the Chronic Reliance on Affective and Cognitive Information," Journal of Experimental Social Psychology, vol. 40, pp. 82-90, 2004.

[33] John, G. and T. Reve, "The Reliability and Validity of Key Informant Data from Dyadic Relationships in Marketing Channels," Journal of Marketing Research, vol. 19, pp. 517-524, 1982.

[34] Johnson, B.; E. Lorenz and B. Lundvall, "Why all this Fuss about Codified and Tacit Knowledge?" Industrial and Corporate Change, vol. 11, pp. 245-262, 2002.

[35] Johnson, D. and K. Grayson, "Cognitive and Affective Trust in Service Relationships," Journal of Business Research, vol. 58, pp. 500-507, 2005.

[36] Katz, J. S. and B. R. Martin, "What is Research Collaboration?" Research Policy, vol. 26, pp. 1-18, 1997.

[37] Katz, R. and T. J. Allen, "Investigating the Not Invented here (NIH) Syndrome: A Look at the Performance, Tenure, and Communication Patterns of $50 \mathrm{R} \& \mathrm{D}$ Project Groups," R\&D Management, vol. 12, pp. 7-20, 1982.

[38] Lane, P. J. and M. Lubatkin, "Relative Absorptive Capacity and Interorganizational Learning," Strategic Management Journal, vol. 19, pp. 461, 1998.

[39] Lundvall, B. and B. Johnson, "The Learning Economy," Journal of Industry Studies, vol. 1, pp. 23-42, 1994.

[40] McGuire, W. J., "The Vicissitudes of Attitudes and Similar Representational Constructs in Twentieth Century Psychology," European Journal of Social Psychology, vol. 16, pp. 89-130, 1986.

[41] Menzel, M., "Dynamic Proximities - Changing Relations by Creating and Bridging Distances," Papers in Evolutionary Economic Geography, vol. 08162008.

[42] Min, S.; A. S. Roath; P. J. Daugherty; S. E. Genchev; H. Chen; A. D. Arndt et al., "Supply Chain Collaboration: What's Happening?" International Journal of Logistics Management, vol. 16, pp. 237-256, 2005.

[43] Moodysson, J. and O. Jonsson, "Knowledge Collaboration and Proximity the Spatial Organization of Biotech Innovation Projects," European Urban \& Regional Studies, vol. 14, pp. 115-131, 2007.

[44] Noteboom, B., Inter-Firm Collaboration, Learning \& Networks - An Integrated Approach, London: Routledge, 2004.

[45] O'Grady, S. and H. W. Lane, "The Psychic Distance Paradox," Journal of International Business Studies, vol. 27, pp. 309-333, 1996.
[46] O'Leary, M. B. and J. N. Cummings, "The Spatial, Temporal, and Configurational Characteristics of Geographic Dispersion in Teams," MIS Quarterly, vol. 31, pp. 433-452, 2007.

[47] Polzer, J. T.; C. B. Crisp; S. L. Jarvenpaa and J. W. Kim, "Extending the Faultline Model to Geographically Dispersed Teams: How Colocated Subgroups can Impair Group Functioning," Academy of Management Journal, vol. 49, pp. 679-692, 2006.

[48] Ponds, R.; F. van Oort and K. Frenken, "The Geographical and Institutional Proximity of Research Collaboration," Papers in Regional Science, vol. 86, pp. 423-443, 2007.

[49] Samuelson, W. and R. Zeckhauser, "Status Quo Bias in Decision Making," Journal of Risk \& Uncertainty, vol. 1, pp. 7-59, 1988.

[50] Shearmur, R., "Innovation, Regions and Proximity: From NeoRegionalism to Spatial Analysis," Regional Studies, vol. 45, pp. 1225$1243,2011$.

[51] Sheehan, K. B. and S. J. McMillan, "Response Variation in E-Mail Surveys: An Exploration," Journal of Advertising Research, vol. 39, pp. 45-54, 1999.

[52] Siebdrat, F.; M. Hoegl and H. Ernst, "Subjective Distance and Team Collaboration in Distributed Teams," Journal of Product Innovation Management, vol. 31, pp. 765-779, 2014.

[53] Teasley, S. and S. Wolinsky, "Communication. Scientific Collaborations at a Distance," Science, vol. 292, pp. 2254-2255, 2001.

[54] Torre, A. and J. Gilly, "On the Analytical Dimension of Proximity Dynamics," Regional Studies, vol. 34, pp. 169-180, 2000.

[55] Torre, A. and A. Rallet, "Proximity and Localization," Regional Studies, vol. 39, pp. 47-59, 2005.

[56] vom Stein, N. and N. Sick, "Technological Distance in Academic Collaborations: Evidence from Battery Research," International Journal of Innovation Management, vol. 18, pp. 1440011-1-144001122, 2014.

[57] vom Stein, N.; N. Sick and J. Leker, "How to Measure Technological Distance in Collaborations - the Case of Electric Mobility," Technological Forecasting and Social Change, vol. 97, pp. 154-167, 2015.

[58] Walker, G.; B. Kogut and W. Shan, "Social Capital, Structural Holes and the Formation of an Industry Network," Organization Science, vol. 8, pp. 109-125, 1997.

[59] Wilson, J. M.; M. B. O'Leary; A. Metiu and Q. R. Jett, "Perceived Proximity in Virtual Work: Explaining the Paradox of Far-but-Close," Organization Studies, vol. 29, pp. 979-1002, 2008. 